\title{
Risk Factors for Acute Kidney Injury in Intensive Care Units
}

\section{Chia Ter Chao*}

Department of Internal Medicine, National Taiwan University Hospital, Taipei, Taiwan
Keywords: Acute Kidney Injury (AKI); Creatinine; Intensive Care Unit (ICU)

In critical care settings, patients with acute kidney injury (AKI) constitute an important subgroup, in that they have higher shortand long-term mortality, prolonged hospital length of stay, and more resource consumption [1,2]. Incidence of AKI in intensive care unit (ICU) patients ranges between $20-70 \%$ according to settings, and, among these, patients who undergo renal replacement therapy (RRT) portend even worse outcome [3]. RRT-treated AKI patients have on average $50-70 \%$ in-hospital mortality (depending on AKI etiologies), and $25-50 \%$ patients develop chronic kidney disease (CKD) thereafter without complete recovery of renal function $[1,3,4]$. Consequently, better understanding of the precipitating factors of AKI in these critically ill patients is of paramount importance for clinicians to reduce the incidence of AKI in ICUs.

Risk factors for AKI in patients with severe illnesses are often multiple rather than single. These features can be grouped into several categories: first, certain underlying background predisposes patients to the development of AKI. Aged patients tend to acquire AKI more frequently than their younger counterparts, owing to the physiologic ageing of kidneys, multiple morbidities, and impaired renal recoverability [5]. Comorbidities include those with underlying diabetes mellitus (DM), hypertension, chronic kidney disease (CKD), and heart failure all reportedly set the backstage of subsequent renal injury, through the interplay of disrupted renal auto-regulation, preexisting renal damage, and concomitant use of nephrotoxic medications $[6,7]$. Interestingly, as CKD often leads to AKI, AKI at its end begets CKD [8]. Also, "cardiorenal syndrome" has been another heated topic in the research field, after the introduction of the conceptually divided five cardiorenal-syndrome subtypes [9]. To complicate the situations, these morbidities usually come hand-in-hand in the modern society, since metabolic syndrome prevails with Westernization of lifestyles globally. It is then difficult to disentangle the complex of "which should be responsible for AKI" most of the time, but it could be helpful for clinicians to recognize these factors and modify them if feasible.

Second, the insult per se can be the precipitant of AKI through different mechanisms. For example, sepsis or systemic inflammatory response syndrome (SIRS) contributes to AKI development, by means of its glomerular hemodynamic alterations, induction of reactive oxygen species and oxidative stresses, and tubular ischemic injury (which is now considered a secondary event) [10]. Hypotension, shock at presentation, and use of vasopressors/inotropes, also account for part of the clinical settings that subsequently spawn AKI [6,7]. Intuitively, these presentations or medical maneuvers reduce renal perfusion and lead to renal ischemia, but the effect of overwhelmed renal autoregulation by renal vessel selectivity could, in fact, be more important. Several high-risk procedures or operations, such as cardiac surgeries (with cardio-pulmonary bypass), emergent surgeries, or lengthy surgery period, serve as a predisposing factor for AKI after operations [11]. Transfusion with packed red blood cells or use of furosemide perioperatively could also be associated with AKI $[11,12]$. The effect of perioperative transfusion is especially worth mentioning, since transfused erythrocytes may already carry structural or functional changes that occur during prolonged storage, and lead to premature clearance from circulation, with release of unbound hemoglobin and paradoxically stimulation of inflammatory cascade [12]. Iron overload could also play a role in the pathophysiology.

Third, medications are often the one neglected component of the preludes for AKI. Angiotensin-converting enzyme inhibitors or angiotensin receptor blockers constitute one important example. Their use during coronary angiography is reported to increase risk of subsequent contrast induced nephropathy by nearly 50\% [13]. Prolonged diuretics use in patients with heart failure or CKD can cause volume depletion and secondary renal ischemia, with resultant AKI susceptibility. Non-steroidal anti-inflammatory agents also predispose one to AKI through their selective renal hemodynamic changes, especially for hypoalbuminemic and anemic patients [14]. Combination of the above agents further raises the AKI risk up to $30 \%$, especially within the initial one month of starting these medications [15]. Consequently, patients in current use of any combination of the above drugs should be attended to, especially during periods of potential renal insults, in order to reduce the incidence of subsequent AKI.

In conclusion, patients with AKI before and during their ICU stay carry a significantly worse outcome than their non-AKI counterparts. Factors including patients' demographic profile, comorbidities, clinical events occurred and medications they use can all take part in these patients' susceptibility to subsequent AKI. It is prudent for us to be cognizant of these factors and aim at preventing or modifying these factors well before the onset of AKI.

\section{References}

1. Cohen SD, Kimmel PL (2012) Long-term sequelae of acute kidney injury in the ICU. Curr Opin Crit Care 18: 623-628.

2. Hoste EA, de Corte W (2012) AKI patients have worse long-term outcomes, especially in the immediate post-ICU period. Crit Care 16: 148.

3. Clec'h C, Darmon M, Lautrette A, Chemouni F, Azoulay E, et al. (2012) Efficacy of renal replacement therapy in critically ill patients: a propensity analysis. Crit Care 16: R236.

4. Vaara ST, Pettila V, Reinikainen M, Kaukonen KM, Finnish Intensive Care Consortium (2012) Population-based incidence, mortality and quality of life in critically ill patients treated with renal replacement therapy: a nationwide retrospective cohort study in finnish intensive care units. Crit Care 16: R13.

5. Chao CT, Wu VC, Lai CF, Shiao CC, Huang TM, et al. (2012) Advanced age affects the outcome-predictive power of RIFLE classification in geriatric patients with acute kidney injury. Kidney Int 82: 920-927.

6. Bagshaw SM, George C, Bellomo R, o R; ANZICS Database Management Committee (2008) Early acute kidney injury and sepsis: a multicentre evaluation. Crit Care 12: R47.

*Corresponding author: Chia Ter Chao, M.D, Department of Internal Medicine National Taiwan University Hospital, 7 Chung-Shan South Road, Zhong-Zheng District, Taipei 100, Taiwan, Tel: +886 223123456 ext. 63098; Fax: +886 2 23952333; E-mail: b88401084@gmail.com

Received January 02, 2013; Accepted January 05, 2013; Published January 25 2013

Citation: Chao CT (2013) Risk Factors for Acute Kidney Injury in Intensive Care Units. Gen Med (Los Angel) 1: e102. doi: 10.4172/2327-5146.1000e102

Copyright: (๑) 2013 Chao CT. This is an open-access article distributed under the terms of the Creative Commons Attribution License, which permits unrestricted use, distribution, and reproduction in any medium, provided the original author and source are credited. 
7. Chawla LS, Abell L, Mazhari R, Egan M, Kadambi N, et al. (2005) Identifying critically ill patients at high risk for developing acute renal failure: a pilot study. Kidney Int 68: 2274-2280.

8. Leung KC, Tonelli M, James MT (2012) Chronic kidney disease following acute kidney injury-risk and outcomes. Nat Rev Nephrol.

9. Ronco C, McCullough PA, Anker SD, Anand I, Aspromonte N, et al. (2010) Cardiorenal syndromes: an executive summary from the consensus conference of the Acute Dialysis Quality Initiative (ADQI). Contrib Nephrol 165: 54-67.

10. Bellomo R, Wan L, Langenberg C, Ishikawa K, May CN (2011) Septic acute kidney injury: the glomerular arterioles. Contrib Nephrol 174: 98-107.

11. Loef BG, Epema AH, Smilde TD, Henning RH, Ebels T, et al. (2005) Immediate postoperative renal function deterioration in cardiac surgical patients predicts in-hospital mortality and long-term survival. J Am Soc Nephrol 16: 195-200.
12. Vellinga S, Verbrugghe W, De Paep R, Verpooten GA, Janssen van Doorn $\mathrm{K}$ (2012) Identification of modifiable risk factors for acute kidney injury after cardiac surgery. Neth J Med 70: 450-454.

13. Rim MY, Ro H, Kang WC, Kim AJ, Park H, et al. (2012) The effect of reninangiotensin-aldosterone system blockade on contrast-induced acute kidney injury: a propensity-matched study. Am J Kidney Dis 60: 576-582.

14. Moon KW, Kim J, Kim JH, Song R, Lee EY, et al. (2011) Risk factors for acute kidney injury by non-steroidal anti-inflammatory drugs in patients with hyperuricemia. Rheumatology (Oxford) 50: 2278-2282.

15. Lapi F, Azoulay L, Yin H, Nessim SJ, Suissa S (2013) Concurrent use of diuretics, angiotensin converting enzyme inhibitors, and angiotensin receptor blockers with non-steroidal anti-inflammatory drugs and risk of acute kidney injury: nested case-control study. BMJ 346: e8525. 